\title{
Front Matter: Volume 10163
}

, "Front Matter: Volume 10163," Proc. SPIE 10163, Electroactive Polymer Actuators and Devices (EAPAD) 2017, 1016301 (11 May 2017); doi: $10.1117 / 12.2280225$

Event: SPIE Smart Structures and Materials + Nondestructive Evaluation and Health Monitoring, 2017, Portland, Oregon, United States 


\title{
PROCEEDINGS OF SPIE
}

\section{Electroactive Polymer Actuators and Devices (EAPAD) 2017}

\author{
Yoseph Bar-Cohen \\ Editor
}

\section{6-29 March 2017 \\ Portland, Oregon, United States}

Sponsored by

SPIE

Co-sponsored by

OZ Optics, Ltd. (United States)

Polytec, Inc. (United States)

Fiberguide Industries (United States)

Frontiers Media (Switzerland)

\section{Cooperating Organization}

Jet Propulsion Laboratory (United States)

Published by

SPIE 
The papers in this volume were part of the technical conference cited on the cover and title page. Papers were selected and subject to review by the editors and conference program committee. Some conference presentations may not be available for publication. Additional papers and presentation recordings may be available online in the SPIE Digital Library at SPIEDigitallibrary.org.

The papers reflect the work and thoughts of the authors and are published herein as submitted. The publisher is not responsible for the validity of the information or for any outcomes resulting from reliance thereon.

Please use the following format to cite material from these proceedings:

Author(s), "Title of Paper," in Electroactive Polymer Actuators and Devices (EAPAD) 2017, edited by Yoseph Bar-Cohen, Proceedings of SPIE Vol. 10163 (SPIE, Bellingham, WA, 2017) Seven-digit Article CID Number.

ISSN: 0277-786X

ISSN: 1996-756X (electronic)

ISBN: 9781510608115

ISBN: 9781510608122 (electronic)

Published by

SPIE

P.O. Box 10, Bellingham, Washington 98227-0010 USA

Telephone +1 3606763290 (Pacific Time) · Fax +1 3606471445

SPIE.org

Copyright @ 2017 , Society of Photo-Optical Instrumentation Engineers.

Copying of material in this book for internal or personal use, or for the internal or personal use of specific clients, beyond the fair use provisions granted by the U.S. Copyright Law is authorized by SPIE subject to payment of copying fees. The Transactional Reporting Service base fee for this volume is $\$ 18.00$ per article (or portion thereof), which should be paid directly to the Copyright Clearance Center (CCC), 222 Rosewood Drive, Danvers, MA 01923. Payment may also be made electronically through CCC Online at copyright.com. Other copying for republication, resale, advertising or promotion, or any form of systematic or multiple reproduction of any material in this book is prohibited except with permission in writing from the publisher. The CCC fee code is $0277-786 \mathrm{X} / 17 / \$ 18.00$.

Printed in the United States of America.

Publication of record for individual papers is online in the SPIE Digital Library.

\section{SPIE. DIGITAL \\ SPIEDigitalLibrary.org}

Paper Numbering: Proceedings of SPIE follow an e-First publication model. A unique citation identifier (CID) number is assigned to each article at the time of publication. Utilization of CIDs allows articles to be fully citable as soon as they are published online, and connects the same identifier to all online and print versions of the publication. SPIE uses a seven-digit CID article numbering system structured as follows:

- The first five digits correspond to the SPIE volume number.

- The last two digits indicate publication order within the volume using a Base 36 numbering system employing both numerals and letters. These two-number sets start with 00, 01, 02, 03, 04, 05, 06, 07, 08, 09, OA, OB ... OZ, followed by 10-1Z, 20-2Z, etc. The CID Number appears on each page of the manuscript. 


\title{
Contents
}

\author{
ix Authors \\ xiii Conference Committee \\ xvii Introduction \\ xxi Appendix: The 2017 EAP-in-Action Program
}

\section{SESSION 1 EAP AS EMERGING ACTUATORS}

1016303 Electroactive polymers for healthcare and biomedical applications (Keynote Paper) [10163-1]

\section{SESSION 2 SENSORS USING EAP MATERIALS}

1016306 Distributed sensing: multiple capacitive stretch sensors on a single channel [10163-4]

1016307 Monitoring diver kinematics with dielectric elastomer sensors [10163-5]

1016308 Dual sensing-actuation artificial muscle based on polypyrrole-carbon nanotube composite [10163-6]

1016309 Operation tools with dielectric elastomer pressure sensors [10163-7]

\section{SESSION 3 DESIGN METHODS OF PRODUCING EAP MECHANISMS}

10163 OC Integrated sensing and actuation of dielectric elastomer actuator [10163-10]

\section{SESSION 4 PERFORMANCE CHARACTERIZATION OF VARIOUS EAP MATERIALS}

10163 OD Properties of polypyrrole polyvinilsulfate films for dual actuator sensing systems [10163-11]

$10163 \mathrm{OH} \quad$ A mathematical model for an integrated self priming dielectric elastomer generator [10163-15]

\section{SESSION 5 ARTIFICIAL MUSCLE FOR SOFT ROBOTICS}

10163 ol Fused filament 3D printing of ionic polymer-metal composites for soft robotics (Invited Paper) [10163-16] 
$10163 \mathrm{OL}$ A model framework for actuation and sensing of ionic polymer-metal composites: prospective on frequency and shear response through simulation tools [10163-20]

$101630 \mathrm{M}$ A theoretical framework for the study of compression sensing in ionic polymer metal composites [10163-21]

SESSION 6A EAP ACTUATORS

1016300 DEMES rotary joint: theories and applications [10163-22]

$10163 \mathrm{OP}$ Dielectric elastomer actuator for the measurement of cell traction forces with sub-cellular resolution [10163-23]

$101630 Q$ Dielectric elastomer actuator with variable stiffness based on interlaminar electrostatic chucking [10163-24]

10163 OS A torsional artificial muscle from twisted nitinol microwire [10163-26]

\section{SESSION 6B EAP BASED ON DIELECTRIC ELASTOMERS I}

10163 OT Chemically pre-strained dielectric elastomers finite element analysis [10163-27]

10163 OW Super stretchable soft actuator made of twisted and coiled spandex fiber [10163-30]

10163 0X Development of a fatigue testing setup for dielectric elastomer membrane actuators [10163-31]

\section{SESSION 7A 3D PRINTING AS A FABRICATION METHOD}

10163 OY Permanent magnets as biasing mechanism for improving the performance of circular dielectric elastomer out-of-plane actuators [10163-97]

$101630 Z$ 3D printing PLA and silicone elastomer structures with sugar solution support material [10163-33]

1016310 Ras Labs-CASIS-ISS NL experiment for synthetic muscle returned to Earth: resistance to ionizing radiation [10163-118]

1016311 Inkjet printing of carbon black electrodes for dielectric elastomer actuators [10163-35]

SESSION 7B IONIC EAP MATERIALS

1016312 Design of ultra-thin high frequency trilayer conducting polymer micro-actuators for tactile feedback interfaces [10163-36]

iv 
1016313 Temperature and humidity dependence of ionic electroactive polymer actuators [10163-102]

SESSION 8A ANALYSIS AND MODELING EAP ACTUATORS PERFORMANCE

1016316 Rate dependent constitutive behavior of dielectric elastomers and applications in legged robotics (Invited Paper) [10163-40]

1016317 Modeling and simulation of a chemically stimulated hydrogel bilayer bending actuator [10163-41]

1016318 Modeling and experimentally characterizing ionic buoyancy engines [10163-42]

$101631 \mathrm{~A} \quad$ Numerical analysis of helical dielectric elastomer actuator [10163-44]

10163 1C Frequency-domain trade-offs for dielectric elastomer generators [10163-46]

SESSION 8B EAP MATERIALS FABRICATION METHODS AND PROCESSES I

$101631 \mathrm{E} \quad$ Electrospraying and ultraviolet light curing of nanometer-thin polydimethylsiloxane membranes for low-voltage dielectric elastomer transducers [10163-48]

$10163 \mathrm{lF} \quad$ Leakage current, self-clearing and actuation efficiency of nanometer-thin, low-voltage dielectric elastomer transducers tailored by thermal evaporation [10163-49]

$1016311 \quad$ Optimization study for fabrication of micro-scale stacked dielectric elastomer actuators [10163-52]

10163 1K Microfabricated PEDOT trilayer actuators: synthesis, characterization, and modeling [10163-54]

$101631 \mathrm{~L} \quad$ Proposal of a peristaltic micropump using dielectric elastomer actuators fabricated by MEMS technology [10163-98]

SESSION 9A APPLICATIONS OF EAP ACTUATORS TO ROBOTIC MECHANISMS I

$101631 \mathrm{~N} \quad$ Entirely soft dielectric elastomer robots [10163-56]

1016310 Fluid electrodes for submersible robotics based on dielectric elastomer actuators (1st Place SPIE Best Student Paper) [10163-57]

SESSION 9B APPLICATIONS OF EAP ACTUATORS TO VARIOUS MECHANISMS II

$101631 \mathrm{U}$ Design and motion control of bioinspired humanoid robot head from servo motors toward artificial muscles [10163-63] 
10163 1W Energy analysis of a DEAP based cylindrical actuator coupled with a radial negative stiffness spring [10163-65]

$101631 \mathrm{X}$ Development of a soft untethered robot using artificial muscle actuators [10163-66]

$101631 Y \quad$ Electrically tunable window based on microwrinkled ZnO/Ag thin film [10163-67]

1016312 Strong dielectric-elastomer grippers with tension arch flexures [10163-68]

\section{SESSION 1OB APPLICATIONS OF EAP ACTUATORS TO VARIOUS MECHANISMS IV}

1016320 Development of elastomeric flight muscles for flapping wing micro air vehicles (Invited Paper) [10163-69]

$1016321 \quad$ Hydrogels for engineering: normalization of swelling due to arbitrary stimulus [10163-71]

1016322 Exploring dielectric elastomers as actuators for hand tremor suppression [10163-70]

SESSION 11A USE OF EAP IN THE FORM OF FIBERS AND TEXTILE

1016325 A novel sheet actuator using plasticized PVC gel and flexible electrodes [10163-74]

1016326 Mechanical stretch influence on lifetime of dielectric elastomer films [10163-75]

1016327 Development of novel textile and yarn actuators using plasticized PVC gel [10163-76]

SESSION 11B EAP BASED ON DIELECTRIC ELASTOMERS II

1016328 Electrical breakdown phenomena of dielectric elastomers (Invited Paper) [10163-77]

1016329 Viscoelastic performance of dielectric elastomer subject to different voltage stimulation [10163-78]

$101632 \mathrm{~A}$ Continuum vibration analysis of dielectric elastomer membranes [10163-79]

10163 2B Electrical breakdown detection system for dielectric elastomer actuators [10163-80]

SESSION 12A APPLICATIONS OF EAP ACTUATORS TO VARIOUS MECHANISMS V

10163 2C New approach to improve the energy density of hybrid electret-dielectric elastomer generators [10163-81]

10163 2D A dielectric elastomer actuator-based tactile display for multiple fingertip interaction with virtual soft bodies [10163-82] 
$101632 \mathrm{G}$ Surface texture change on-demand and microfluidic devices based on thickness mode actuation of dielectric elastomer actuators (DEAs) [10163-85]

$101632 \mathrm{H} \quad$ Rubbery computing [10163-86]

$1016321 \quad$ Effect of porosity of the electrodes on ionic electroactive polymer actuators [10163-101]

SESSION 12B EAP MATERIALS FABRICATION METHODS AND PROCESSES II

$101632 \mathrm{~K} \quad$ Stackable configurations of artificial muscle modules that is continuously-tunable by voltage (Invited Paper) [10163-88]

$101632 \mathrm{~L} \quad$ Micro-fabrication of a novel linear actuator [10163-89]

$101632 \mathrm{M}$ Effect of electrical terminals made of copper to the ionic electroactive polymer actuators [10163-90]

$101632 \mathrm{~N} \quad$ Fabrication of multilayered conductive polymer structures via selective visible light photopolymerization [10163-91]

1016320 Design and fabrication of conductive polyaniline transducers via computer controlled direct ink writing [10163-92]

$101632 \mathrm{P} \quad$ Adhesion enhancement methods for a roll-to-sheet fabrication process of DE stack-transducers and their influences on the electric properties [10163-93]

POSTER SESSION

$101632 Q \quad$ Fabrication of dielectric elastomer stack transducers (DEST) by liquid deposition modeling [10163-94]

$101632 R \quad$ Boundary-condition analysis for physics-based modeling of ionic-polymer metal composite electroactive polymers [10163-95]

$101632 \mathrm{~T} \quad$ Study on simplification of a multi-physical model of IPMC sensor generating voltage as sensing signal [10163-99]

$101632 \mathrm{U} \quad$ Experimental verification of displacement control on integrated ionic polymer-metal composite actuators with stochastic on/off controller [10163-100]

$101632 \mathrm{~V}$ Position control of twisted and coiled polymer actuator using a controlled fan for cooling [10163-103]

10163 2W Elastic actuation for legged locomotion [10163-104]

1016331 Energy harvesting by dielectric elastomer generator and self-priming circuit: verification by radio transmission [10163-110]

1016332 Micromixer based on dielectric stack actuators for medical applications [10163-112] 
1016335 Effects of ionic liquids on the performance of IPMC [10163-115]

1016338 Experience-based learning on determining the frictional coefficients of thermoset polymers incorporated with silicon carbide whiskers and chopped carbon fibers at different temperatures [10163-119]

1016339 Experience-based training of students on concretes reinforced by recycled carbon fibers [10163-120] 


\section{Authors}

Numbers in the index correspond to the last two digits of the seven-digit citation identifier (CID) article numbering system used in Proceedings of SPIE. The first five digits reflect the volume number. Base 36 numbering is employed for the last two digits and indicates the order of articles within the volume. Numbers start with 00, 01, 02, 03, 04, 05, 06, 07, 08, 09, 0A, 0B...0Z, followed by 10-1Z, 20-2Z, etc.

Aabloo, Alvo, 13, 21, 2M

Ahmed, Anansa S., $1 \mathrm{Z}$

Akle, Barbar J., 18

Alamir, Mohammed, 38

Albers, Leila N., 10

Almubarak, Yara, $1 \mathrm{U}$

Alzahrani, Naif, 38, 39

Anderson, lain A., 06, 07, 0H, 1N, 2H

Ankit, Ankit, 2G

Arakawa, Takeshi, 2V

Asai, K., 1L

Asaka, Kinji, 2T, 2V

Ascione, George, 10

Asmatulu, Eylem, 39

Asmatulu, Ramazan, 38

Asundi, Anand, IY

Bardella, Lorenzo, OM

Bass, Patrick S., 2R

Baver, Siegfried G., 03

Blocher, Whitney, 10

Bochmann, Helge, 2P

Böse, Holger, 09

Boys, Hugh, 2D

Busfield, James J. C., 2B, 2D

Cai, Shengqiang, 10

Cao, Chongjing, $2 \mathrm{~W}$

Cao, Jiawei, $1 \mathrm{X}$

Carpi, Federico, 2B, 2D

Carrico, James D., Ol

Cattan, Eric, $1 \mathrm{~K}$

Cha, Youngsu, OM

Chavanne, Jonathan, IW

Chen, Hualing, 29

Chen, Zheng, OC

Cheng, Zhongyang, 2R

Chin, Yao-Wei, 20

Cho, Kyeong Ho, OW

Choi, Hyouk Ryeol, OW

Christianson, Caleb, 10

Civet, Yoan, IW

Clark, Jonathan, 16

Conn, Andrew, 2W

Corbaci, Mert, 11

Corl, Dylan, 10

Cosgun, Cumhur, 39

Cullen, Andrew T., 2N

Cylinder, David, 10

Ebrahimi Takalloo, Saeedeh, 12

Ehrenhofer, Adrian, 21
Ehrlich, Johannes, 09

Eom, S. I., $1 \mathrm{~L}$

Fang, Houfei, 2L

Förster-Zügel, Florentine, 2Q, 32

Frediani, Gabriele, 2D

Froio, Danielle, 10

Fuerst, Tyler, 10

Furuse, A., 27

Gallucci, Sergio, 10

Gao, Wei, 16

Gaza, Ramona, 10

Gentile, Charles, 10

Ghilardi, Michele, 2B

Goldberg, Nathaniel, 10

Grondel, Sébastien, 1K

Hablani, Surbhi, 10

Hamidi, Armita, $\mathrm{OZ}$

Hao, Zhaogang, 00

Harrison, Edward, 38

Hashimoto, Minoru, 25, 27

Heng, Kim-Rui, 12

Henke, E.-F. Markus, $\mathrm{OH}, 1 \mathrm{~N}, 2 \mathrm{H}$

Hijazi, Ahmad, 18

Hill, M., OX

Hitchner, Robert, 10

Hoffman, Dan, 10

Holness, F. Benjamin, 20

Homer, Martin, 1C

Hou, Yangqing, 2L

Huang, Bo, 00

Hunter, Ian W., OS

Hussaini, M. Yousuff, 16

lannarelli, A., 26

Ikegame, Toru, 31

Illenberger, Patrin $\mathrm{K}$., $\mathrm{OH}$

Imamura, Hiroya, OQ

Ito, Takamasa, 31

Jain, Shrenik, $\mathrm{OZ}$

Jean-Mistral, Claire, 2C

Jiang, Shuidong, $2 \mathrm{~L}$

Johanson, Urmas, 2I, 2M

Jung, Hosang, OW

Kadooka, Kevin, $0 Q$

Kamamichi, Norihiro, $2 \mathrm{U}$

Kauffman, Jeffrey L., 22

Kelley, Christopher R., 22

Kim, Daewon, 1A

Kim, J.-W., 1L

Kim, Kwang J., OL 
Kim, Min Jung, 35

Kim, Youngeun, OW

Kimura, Keishiro, 2U

Klug, Florian, 2Q, 32

Koh, Soo Jin Adrian, 2K

Kojima, Hiroki, 31

Koo, Ja Choon, OW

Kovacs, Gabor, $1 \mathrm{E}$

Krutz, Gary, OT

La, Thanh-Giang, 20

Lagomarsini, Clara, 2C

Lamkin-Kennard, Kathleen, 11

Lau, Gih-Keong, 1Y, 1Z, 20

Leang, Kam K., Ol

Lee, Heow Pueh, $1 \mathrm{X}$

$\mathrm{Li}, \mathrm{Bo}, 29$

Li, Mingyu, 00

$\mathrm{Li}, \mathrm{Yi}, 25$

Liffland, Stephanie, 10

Liu, Lei, 29

Liu, Lei, $2 \mathrm{~L}$

Loew, P., OY

Lörcher, Samuel, $1 \mathrm{~F}$

Maas, Jürgen, $2 \mathrm{P}$

Madawala, Udaya K., $\mathrm{OH}$

Madden, John D. W., 12, $1 \mathrm{~K}$

Mark, Patrick S., 10

Mashayekhi, Somayeh, 16

Masuya, Ken, 2V

Mateiu, Ramona V., 28

Mathew, Anup Teejo, 2K

Mathews, Nripan, 2G

Meixler, Lewis D., 10

Menegus, Michael J., 10

Miles, Paul, 16

Mirvakili, Seyed M., OS

Miyata, K., 1L

Monfray, Stephane, 2C

Moon, Hyungpil, OW

Mößinger, Holger, 2Q, 32

Moy, Leon, 10

Müller, Bert, 1E, 1F

Müller, Dominik, 09

Nah, Changwoon, 35

Nair, Saurabh, 1A

Nakshatharan, S. Sunjai, 13, 21, 2M

Nalbach, S., 2A

Nam, Jae-Do, OW

Nasser, Jalal, 18

Newell, Brittany, OT

Nguyen, Anh Chien, 2G

Nguyen, Ngoc Tan, $1 \mathrm{~K}$

Niasar, M. Ghaffarian, 26

Nodarse, Robert, 10

Oates, William, 16

Osmani, Bekim, 1E, $1 \mathrm{~F}$

Otero, Toribio F., 08, OD

Park, Jang Ho, $1 \mathrm{~A}$

Park, Sang Woo, 35

Pascal, Kevin, OT
Pascual, Victor H., 08, OD

Patlolla, Vamsidhar R., 39

Perriard, Yves, IW

Plesse, Cédric, $1 \mathrm{~K}$

Poirier, Catherine, 10

Porfiri, Maurizio, OM

Poslad, Stefan, 2D

Poulin, Alexandre, $\mathrm{OP}$

Price, Aaron D., 2N, 20

Prillaman, Daniel L., 10

Punning, Andres, 13, 21, 2M

Qin, Lei, 1X

Rasmussen, Lenore, 10

Ratto, Jo Ann, 10

Rizzello, G., OX, OY, 2A

Rodella, Andrea, OM

Rodriguez, Simone, 10

Rosset, Samuel, OP, 11

Rossiter, Jonathan, 1C

Schlaak, Helmut F., 2Q, 32

Schlatter, Samuel, 11

Schumacher, J., 08, OD

Seelecke, S., OX, OY, 2A

Seifi, Hasti, 12

Shea, Herbert, OP, 11

Shen, Qi, OL

Sheng, Junjie, 29

Shrestha, Milan, 1Y, 12

Siketanc, Matej, $1 \mathrm{E}$

Sinkler, Charles, 10

Skov, Anne L., 28

Slipher, Geoffrey A., 2H

Smith, Michael, OP

Sobczyk, Martin, 17

Solano-Arana, Susana, 2Q, 32

Song, Min Geun, OW

Soyer, Caroline, 1K

Stalbaum, Tyler, OL

Stewart, Frank, OT

Sun, Lining, 00

Sylvestre, Alain, 2C

Tadesse, Yonas, 0Z, $1 \mathrm{U}$

Tahara, Kenji, 2V

Tairych, Andreas, 06

Takagi, Kentaro, 2T, 2V, 31

Takeda, Jun, 2T, 2V

Taya, Minoru, $0 Q$

Taylor, James, 10

Thellen, Christopher T., 10

Tolley, Michael T., 10

Töpper, Tino, 1E, 1F

Valenza, Logan, 10

Vidal, Frédéric, $1 \mathrm{~K}$

Vo Tran, Vy Khanh, 2K

Volpini, Valentina, $0 \mathrm{M}$

von Heckel, Benedikt, $2 \mathrm{P}$

Walker, Christopher R., 07

Wallmersperger, Thomas, 17, 21

Walter, Wayne, 11

Wang, Shu, 00 
Wilson, Katherine E., $\mathrm{OH}, 1 \mathrm{~N}, 2 \mathrm{H}$

Won, Joohye, 35

Yang, Sang Yul, OW

Ye, Zhihang, $\mathrm{OC}$

Yoshida, K., $1 \mathrm{~L}$

Yoshikawa, Hitoshi, 31

Yu, Liyun, 28

Zanini, Plinio, $1 \mathrm{C}$

Zeineddine, Hatim F., 39

Zhang, Lin, $2 R$

Zhang, Yuqing, 29

Zhao, Jianwen, 00

Zhu, Jian, $1 \mathrm{X}$

Zhu, Zicai, 2T

Zollinger, Alicia, OP

Proc. of SPIE Vol. 10163 1016301-11

Downloaded From: https://www.spiedigitallibrary.org/conference-proceedings-of-spie on 26 Apr 2023 Terms of Use: https://www.spiedigitallibrary.org/terms-of-use 
Proc. of SPIE Vol. 10163 1016301-12 Downloaded From: https://www.spiedigitallibrary.org/conference-proceedings-of-spie on 26 Apr 2023
Terms of Use: https://www.spiedigitallibrary.org/terms-of-use 


\title{
Conference Committee
}

\author{
Symposium Chairs
}

Jayanth N. Kudva, NextGen Aeronautics, Inc. (United States)

Theodoros E. Matikas, University of loannina (Greece)

Symposium Co-chairs

Tribikram Kundu, The University of Arizona (United States)

Gregory W. Reich, Air Force Research Laboratory (United States)

Conference Chair

Yoseph Bar-Cohen, Jet Propulsion Laboratory (United States)

Conference Co-chair

Jonathan M. Rossiter, University of Bristol (United Kingdom)

\section{Conference Program Committee}

Barbar J. Akle, Lebanese American University (Lebanon) Iain A. Anderson, The University of Auckland (New Zealand)

Tunku Ishak Al-Irsyad, University Teknologi MARA (Malaysia)

Kinji Asaka, National Institute of Advanced Industrial Science and Technology (Japan)

Pavol Baver, Technische Universiteit Delft (Netherlands)

Siegfried G. Bauer, Johannes Kepler Universität Linz (Austria)

Ray H. Baughman, The University of Texas at Dallas (United States)

Václav Bouda, Czech Technical University in Prague (Czech Republic)

Federico Carpi, Università degli Studi di Firenze (Italy)

Suresh Chandra, Institute of Technology, Banaras Hindu University (India)

Hyouk Ryeol Choi, Sungkyunkwan University (Korea, Republic of)

Gal deBotton, Ben-Gurion University of the Negev (Israel)

Toribio Fernández Otero, Universidad Politécnica de Cartagena (Spain)

Yahya A. Ismail, A'Shargiyah University (Oman)

Edwin W. H. Jager, Linköping Universitet (Sweden)

Giedrius Janusas, Kaunas University of Technology (Lithuania)

Kwang Jin Kim, University of Nevada, Las Vegas (United States)

Gabor M. Kovacs, EMPA (Switzerland)

Maarja Kruusmaa, University of Tartu (Estonia)

Jinsong Leng, Harbin Institute of Technology (China)

John D. W. Madden, The University of British Columbia (Canada)

Qibing Pei, University of California, Los Angeles (United States)

Thelge Chaminda Peiris, MAS Innovation Ltd. (Sri Lanka)

Valentin Radu, Omicron Plus S.R.L. (Romania) 
Mehdi Razzaghi-Kashani, Tarbiat Modares University

(Iran, Islamic Republic of)

Anuvat Sirivat, Chulalongkorn University (Thailand)

Anne Ladegaard Skov, Technical University of Denmark (Denmark)

Ji Su, NASA Langley Research Center (United States)

Minoru Taya, University of Washington (United States)

I-Hsiang Tseng, Feng Chia University (Taiwan)

Rocco Vertechy, Università degli Studi di Bologna (Italy)

Frédéric Vidal, Université de Cergy-Pontoise (France)

Gordon G. Wallace, University of Wollongong (Australia)

Thomas Wallmersperger, Technische Universität Dresden (Germany)

Qiming M. Zhang, The Pennsylvania State University (United States)

Jian Zhu, National University of Singapore (Singapore)

Pawel Zylka, Wroclaw University of Technology (Poland)

Session Chairs

1 EAP as Emerging Actuators

Yoseph Bar-Cohen, Jet Propulsion Laboratory (United States)

Jonathan M. Rossiter, University of Bristol (United Kingdom)

2 Sensors Using EAP Materials

Siegfried G. Bauer, Johannes Kepler Universität Linz (Austria)

Kwang Jin Kim, University of Nevada, Las Vegas (United States)

3 Design Methods of Producing EAP Mechanisms

Anne Ladegaard Skov, Technical University of Denmark (Denmark)

Adrian Koh, National University of Singapore (Singapore)

4 Performance Characterization of Various EAP Materials

Geoff Spinks, University of Wollongong (Australia)

Stoyan Smoukov, University of Cambridge (United Kingdom)

$5 \quad$ Artificial Muscle for Soft Robotics

Kwang Jin Kim, University of Nevada, Las Vegas (United States)

Maurizio Porfiri, NYU Tandon School of Engineering (United States)

6A EAP Actuators

Gabor M. Kovacs, EMPA (Switzerland)

Christoph Keplinger, University of Colorado Boulder (United States)

6B EAP Based on Dielectric Elastomers I

Richard J. Spontak, North Carolina State University (United States)

Barbar J. Akle, Lebanese American University (Lebanon)

7A 3D Printing as a Fabrication Method

William S. Oates, Florida State University (United States)

Richard J. Spontak, North Carolina State University (United States) 
Ionic EAP Materials

Iain A. Anderson, The University of Auckland (New Zealand)

Samuel Rosset, École Polytechnique Fédérale de Lausanne (Switzerland)

8A Analysis and Modeling EAP Actuators Performance

John D. W. Madden, The University of British Columbia (Canada)

Gih-Keong Lau, Nanyang Technological University (Singapore)

8B EAP Materials Fabrication Methods and Processes I

Qibing Pei, University of California, Los Angeles (United States)

Geoffrey M. Spinks, University of Wollongong (Australia)

9A Applications of EAP Actuators to Robotic Mechanisms I

Lenore Rasmussen, Ras Laboratories, LLC (United States)

Jonathan M. Rossiter, University of Bristol (United Kingdom)

9B Applications of EAP Actuators to Various Mechanisms II

Bert Müller, University of Basel (Switzerland)

Gih-Keong Lau, Nanyang Technological University (Singapore)

10A Applications of EAP Actuators to Various Mechanisms III

Holger Böse, Fraunhofer-Institut für Silicatforschung ISC (Germany)

E.-F. Markus Henke, The University of Auckland (New Zealand)

10B Applications of EAP Actuators to Various Mechanisms IV

Liwu Liu, Harbin Institute of Technology (China)

Jian Zhu, National University of Singapore (Singapore)

11 Use of EAP in the Form of Fibers and Textile

Dan Armstrong, North Carolina State University (United States)

Richard J. Spontak, North Carolina State University (United States)

11 B EAP Based on Dielectric Elastomers II

Rocco Vertechy, Università degli Studi di Bologna (Italy)

Kam K. Leang, The University of Utah (United States)

12A Applications of EAP Actuators to Various Mechanisms $V$

Jinsong Leng, Harbin Institute of Technology (China)

Seyed Mohammad Mirvakili, Massachusetts Institute of Technology (United States)

12B EAP Materials Fabrication Methods and Processes II

Jonathan M. Rossiter, University of Bristol (United Kingdom)

Seon Jeong Kim, Hanyang University (Korea, Republic of) 
Proc. of SPIE Vol. 10163 1016301-16 Downloaded From: https://www.spiedigitallibrary.org/conference-proceedings-of-spie on 26 Apr 2023
Terms of Use: https://www.spiedigitallibrary.org/terms-of-use 


\section{Introduction}

The SPIE Electroactive Polymers Actuators and Devices (EAPAD) conference remains the leading international forum for presenting the latest progress and information exchange among the attendees regarding the advances, capabilities, challenges and potential future directions. The conference this year was chaired by Yoseph Bar-Cohen, Jet Propulsion Laborotary/California Institute of Technology (United States), and co-chaired by Jonathan M. Rossiter, University of Bristol (United Kingdom). Hani E. Naguib, a notable award recipient within the Smart Structures symposium, University of Toronto, Canada (Figure 1) received the 2017 SPIE Fellow Award for his contributions to multifunctional materials development and characterization including EAP materials.

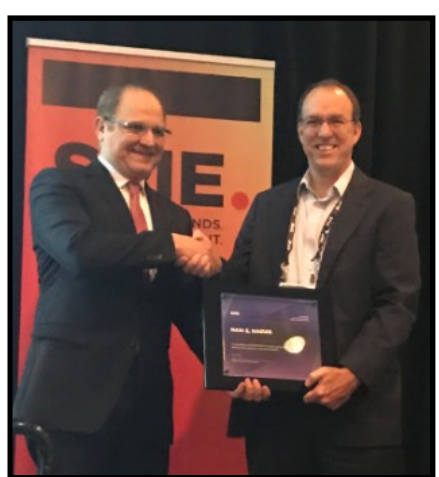

Figure 1: Hani E. Naguib (on the left) receiving the 2017 SPIE Fellow Award from Chris Lynch, University of California, Los Angeles.

Photos from the conference were posted at the SPIE website: http://spie.org/about-spie/press-room/spie-smart-structures/nondestructiveevaluation-2017-news-and-photos

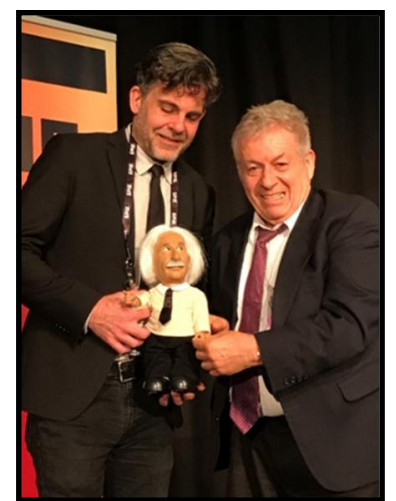

Figure 2: David Hanson and Yoseph Bar-Cohen next to a toy robot Prof. Einstein
The conference included 122 presentations and was well attended by internationally leading experts in the field including members of academia, industry, and government agencies from the United States and overseas. This year, two plenary speakers made EAPrelated presentations at the symposium. David Hanson (Figure 2), Hanson Robotics, presented "Electroactive polymers for healthcare and biomedical applications". His presentation included a demonstration of his robot, Sophia, conversing with him and making facial expressions. Hanson pointed out that bio-inspired intelligent robots are coming of age in both research and industry, and are propelling market growth for robots and Al.

However, conventional motors limit the capability of bio-inspired robotics. EAP actuators and sensors could improve the simplicity, compliance, physical scaling, and offer bio-inspired advantages in robotic locomotion, grasping, manipulation, and social expressions. For EAP actuators to realize their transformative potential, further innovations are needed. The actuators must be robust, fast, powerful, manufacturable, and affordable. In his presentation, Hanson reviewed the 
progress, opportunities, and challenges in his latest work with social robots and EAP actuators, and he proposed a roadmap for EAP actuators in bio-inspired intelligent robotics.

In addition, Chiara Daraio, California Institute of Technology (United States), presented a plenary presentation entitled "Plant nanobionic materials for thermally active, soft, artificial skins". In her paper, she described bionic materials as a class that aims to preserve, enhance, and exploit properties of living systems for engineering purposes. In most cases, however, creating synthetic materials that reproduces or surpasses the performance of natural materials has been elusive. In her lab, Daraio fabricated synthetic materials that combine carbon nanoparticles in a matrix of plant cells to create new temperature sensors with record-breaking responsivity. She had extracted the active molecule, pectin (responsible for the temperature sensitivity in plants), to create ultra-sensitive, flexible membranes that can map temperature changes from a distance. These materials augment properties of synthetic skins for robotics and prosthesis, and can find applications in consumer electronics or NDE.

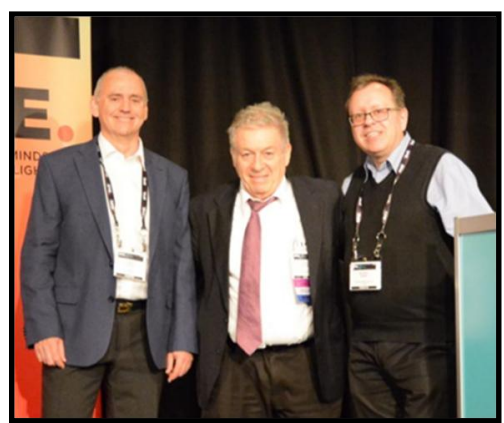

Figure 3: From left to right - Gabor Kovach, Yoseph Bar-Cohen, and Siegfried G. Baver

In the EAPAD conference, the keynote speaker was Siegfried G. Baver (Figure 3), Johannes Kepler Universität, Linz (Austria) with a paper titled "Electroactive polymers for healthcare and biomedical applications". In his paper, he noted that electroactivity has been noticed in biological substances; including proteins, polynucleotides and enzymes. In addition, piezo- and pyroelectricity were found in wool, hair, wood, bone and tendon. He stated that there is still a strong debate about the physiological importance of electroactive effects in biological materials, but it is interesting that electroactive phenomena are widespread in natural materials. According to Baver with the currently available science and technology, we are at the verge of witnessing the demonstration of truly complex bionic systems and the future of EAP materials remains bright.

Overall, the presented papers reported the significant progress made in each of the topics of the EAP field infrastructure. The topics included: theoretical modeling and analysis of EAP mechanisms; improved EAP materials, processes, fabrication (including 3D printing) and characterization techniques; emerging EAP actuators (including ionic, conducting, shape memory polymers, CNT and dielectric EAP); applications of EAP materials including power generation and energy harvesting, robotics, haptic, tactile, and other sensors. Of significant interest, Gabor M. Kovacs, EMPA (Switzerland), (Figure 3) presented a paper entitled "From research to production" in which he described his company efforts to create a commercial EAP actuator at mass production scale and the related issues. 
The efforts described in the presented papers show significant improvements in understanding the electromechanical principles towards better methods of dealing with the challenges to the materials applications. Researchers continue to develop analytical tools and theoretical models to describe the electrochemical and mechanical processes, nonlinear behavior as well as methodologies of design and control of the activated materials. EAP with improved response were described including dielectric elastomer, IPMC, conducting polymers, gel EAP, carbon nanotubes, and other types. Specifically, there seems to be a significant trend towards using dielectric elastomers as practical EAP actuators. The invited papers in the 2017 EAPAC Conference were as follows:

Gabor M. Kovacs, EMPA (Switzerland), "From research to production" [10163-2];

John D. W. Madden, Yuta Dobashi, Mirza S. Sarwar, Eden C. Preston, Justin K. M. Wyss, The Univeristy of British Columbia (Canada); Vincent Woehling, Tran-Minh-Giao Nguyen, Cédric Plesse, Frédéric Vidal, Université de Cergy-Pontoise (France); Sina Naficy, Geoffrey M. Spinks, University of Wollongong (Australia), "Proximity and touch sensing using deformable ionic conductors" [10163-3];

Stoyan Smoukov, University of Cambridge (United Kingdom), "Bottom-up approaches to multi-functional materials and artificial morphogenesis" [10163-8];

James D. Carrico, Kam K. Leang, The University of Utah (United States), "Fused filament 3D printing of ionic polymer-metal composites for soft robotics" [10163-16];

William S. Oates, Paul Miles, Wei Gao, Jonathan Clark, Somayeh Mashayekhi, Mohammad Y. Hussaini, Florida State University (United States), "Rate dependent constitutive behavior of dielectric elastomers and applications in legged robotics" [10163-40];

Christoph Keplinger, University of Colorado Boulder (United States), "Reliable, robust, electrically powered soft actuators that self-heal from mechanical and electrical damage" [10163-55];

Seon Jeong Kim, Shi Hyeong Kim, Hanyang University (Korea, Republic of); Ray H. Baughman, The University of Texas at Dallas (United States), "Artificial muscles for electrical energy harvesting" [10163-60];

Gih-Keong Lau, Yao-Wei Chin, Nanyang Technological University (Singapore); Thanh-Giang Lau, Nanyang Technological University 
(Singapore), "Development of elastomeric flight muscles for flapping wing micro air" [10163-69];

Mohammad Vatankhah-Varnosfaderani, William F. M. Daniel, Alexandr P. Zhushma, Qiaoxi Li, Benjamin J. Morgan, The University of North Carolina at Chapel Hill (United States); Krzysztof Matyjaszewski, Carnegie Mellon University (United States); Daniel P. Armstrong, North Carolina State University (United States); Andrey $\mathrm{V}$. Dobrynin, The University of Akron (United States); Sergei S. Sheyko, The University of North Carolina at Chapel Hill (United States); Richard J. Spontak, North Carolina State University (United States), "Bottlebrush elastomers: a promising molecular engineering route to tunable, prestrain-free dielectric elastomers" [1016372];

Ramona Mateiu, Liyun Yu, Anne L. Skov, Technical University of Denmark (Denmark), "Electrical breakdown phenomena of dielectric elastomers" [10163-77];

Vy Khanh Vo Tran, Anup Teejo Mathew, Adrian Koh, National University of Singapore (Singapore), "Stackable configurations of artificial muscle modules that is continuously-tunable by voltage" [10163-88];

The EAP-in-Action Session included 13 demonstrations with presenters from China, Germany, Japan, New Zealand, Singapore, Switzerland, and the United States. The session was opened by Dr. Hanson's robot Sophia, who welcomed the attendees of the session and gave general introductory words. Then, Dr. Hanson presented the new toy robot, Prof. Einstein, and demonstrated its capabilities (Figure 2). This year SPIE started giving awards for the best EAP-in-Action Demonstrations (see Appendix for the details).

A notable accomplishment of the students who participated and made a presentation at the EAPAD conference was winning the Best Student Paper Award. The winner this year, Caleb Christianson, University of California, San Diego, (Figure 4) with his paper titled "Fluid electrodes for submersible robotics based on dielectric elastomer actuators" [10163-57].

In closing, I would like to extend a special thanks to all the conference attendees, paper presenters, session chairs, EAP-inAction Demo presenters, and the members of the EAPAD program organization committee. In addition, special thanks are extended to the SPIE staff that helped making this conference a great success.

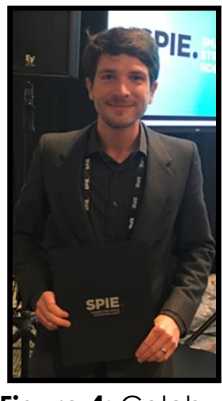

Figure 4: Caleb Christianson, University of California, San Diego, the winner of the Best Student Paper Award 


\section{Appendix: the 2017 EAP-in-Action program}

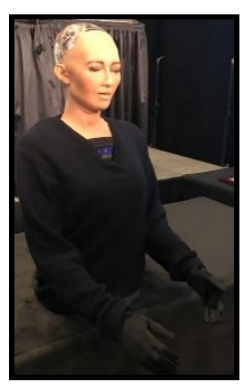

Figure 5:

Hanson's robot, Sophia, greets the attendees of the EAP-in-Action Session.
The 2017 EAP-in-Action session highlighted some of the latest capabilities and applications of Electroactive Polymer (EAP) materials where the attendees have been shown demonstrations of these materials in action. In addition, the attendees were given an opportunity to interact directly with the presenters as well as have been given "hands-on" experience with the presented technology. The first Human/EAP-Robot Armwrestling Contest was held in 2005 during this session.

This year, the session has been opened by Dr. Hanson's robot, Sophia (Figure 5), who welcomed the attendees of the session and gave general introductory words. Then, he presented the new toy robot, Prof. Einstein, and demonstrated its capabilities (Figure 2). This participation of a humanlike robot gave great excitement to the participants with the feeling of the "future is here".

As part of the session, Gabor Kovacs presented his company's new contractile multilayered stack EAP actuator that they are developing towards mass production (Figure 6).

The Session included 13 demonstrations with presenters from China, Germany, Japan, New Zealand, Singapore, Switzerland, and the United States. The presenters consisted of professors and their students as well as engineers from various companies. This year, the session ran as a competition, and the top three presentations were selected by six judges. The winners were as follows:

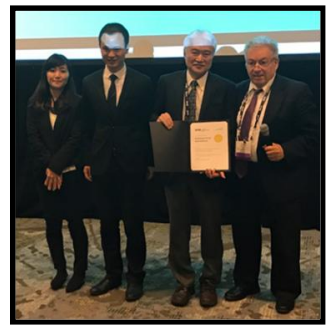

First Place: Multilayered PVC gel artificial muscle - Minoru Hashimoto, Yi Li, Aya Suzuki, Hanako Niwa, Rina Yokotsuka, Shinshu University, Japan (Figure 7, left)

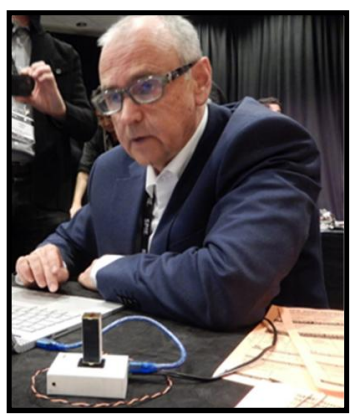

Figure 6: Gabor Kovach presenting his company's new contractile multilayered stack EAP actuator. 
Second Place: DEA-driven vibratory feeder - Steffen Hau, Mathias Hoffmann, Stefan Seelecke, Saarland Universität, Germany (Figure 8, right)
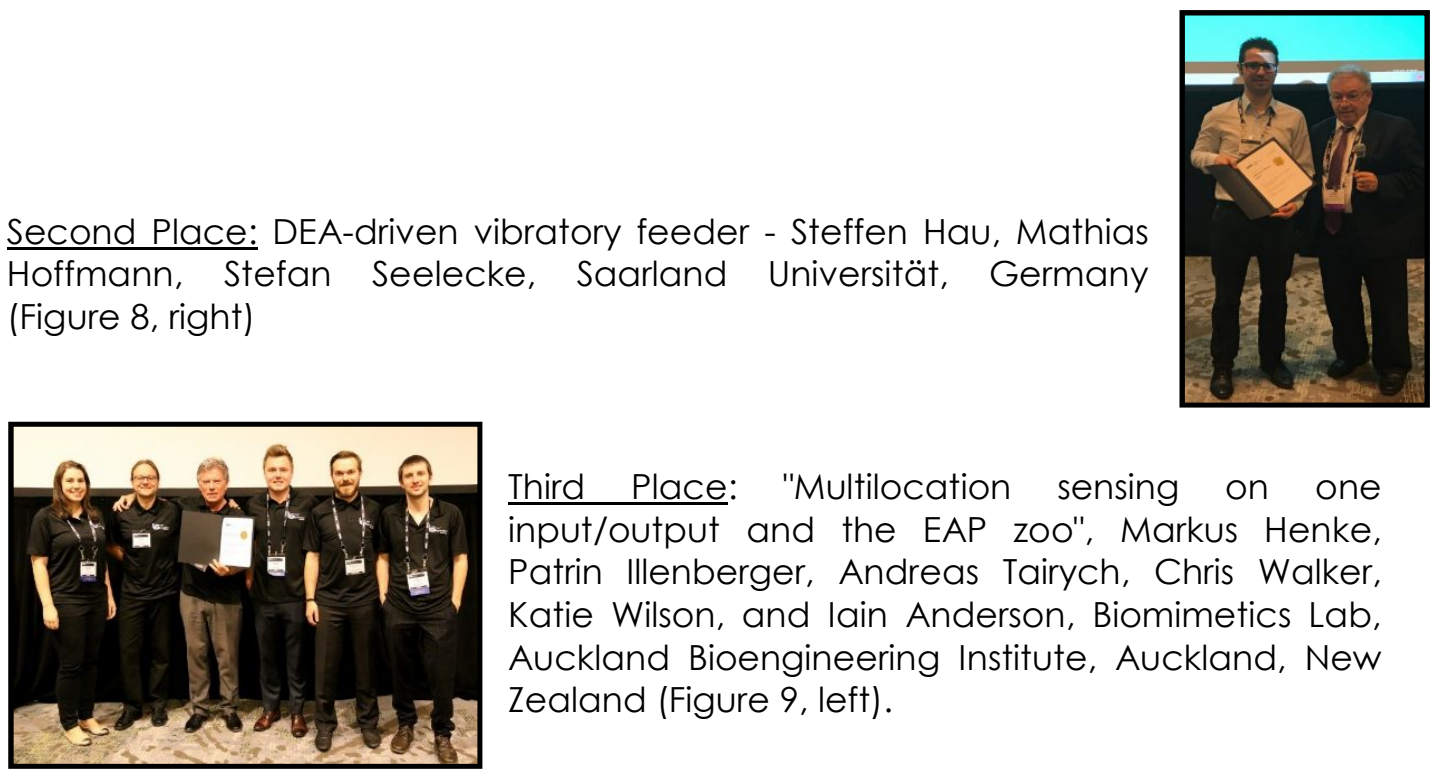

Third Place: "Multilocation sensing on one input/output and the EAP zoo", Markus Henke, Patrin Illenberger, Andreas Tairych, Chris Walker, Katie Wilson, and lain Anderson, Biomimetics Lab, Auckland Bioengineering Institute, Auckland, New Zealand (Figure 9, left).

The ranking evaluation criteria of the demonstration were:
1. Originality/creativity
2. Use of EAP to drive the demo
3. Performance of the demo
4. Potential impact

The judges for the 2017 competition were:

- $\quad$ Siegfried Baver, Johannes Kepler Universität Linz (Austria)

- $\quad$ David Hanson, Hanson Robotics LLC (United States)

- Gabor Kovacs, EMPA (Switzerland)

- John D Madden, The University of British Columbia (Canada)

- $\quad$ Qibing Pei, University of California, Los Angeles (United States)

- Jonathan Rossiter, University of Bristol (United Kingdom)

Presentations were scored as followed: 4 Excellent; 3 Good; 2 Fair; 1 Reasonable; o No Show

The demonstrations in 2017 included innovative devices and potential new products that are driven by EAP and were as follows (listed by the country of the leading presenters):

\section{China}

(Figure 10) Jing Dai, Bangyuan Liu, Feiyu Chen, Sukai Wang, Zhiqiang Fu, Tiefeng Li, Soft Matter Research Center of Zhejiang University, China, "Applications of smart polymers" 


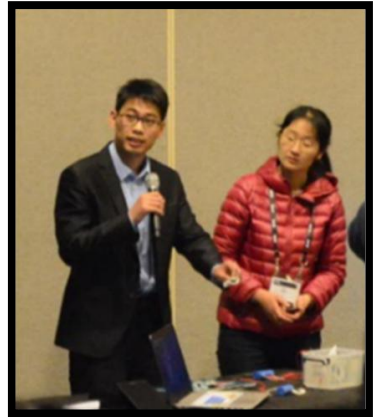

Figure 10: The team from Zhejiang University demonstrating their EAP actuated soft robotic mechanism.

This demonstration showed Soft robotics and smart structures that are made of multiple soft active materials, and can be fabricated by 3D printing method. Driven by dielectric elastomer, the robot shows excellent performances in large actuation and fast response. Using a common compact power and control electronics, various configurations of soft robot can be designed as actuated modules. Smart structures made of temperature active tough hydrogel will also demonstrate as actuators of bio-medical applications. The operation principles may guide the further design of soft robots for various applications.

(Figure 11) Liwu Liu, Jinrong Li, Fengfeng Li, Xiongfei LV, Jinsong Leng, Harbin Institute of Technology, China, "Applications of smart deformable polymers"

This demonstration will show smart polymers in action taking advantage of their being light weight, fast response, and large deformation. These advantages make them attractive for applications in smart bionics, aerospace, biomedicine and other fields. The demonstration will include the applications of EAP, shape memory polymer (SMP) and pneumatic artificial muscle (PAM), such as soft robot, soft continuum manipulator, smart release device, adaptive eyewear frame and other deformable structures.

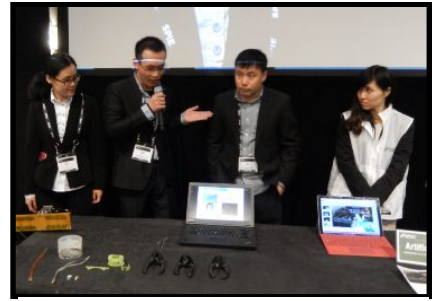

Figure 11: Hui Gao, Fanlong Chen (speaker), Liwu Liu (from left to right) (Harbin Institute of Technology), presenting the demo "Applications of smart deformable polymers"

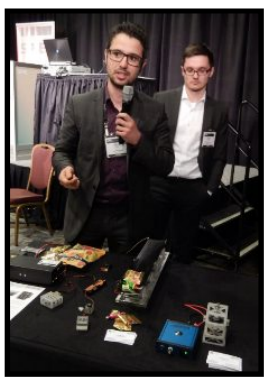

Figure 12: Steffen Hau, Saarland Univ. (Germany), presenting the DEA Driven Vibratory Feeder demo.

\section{Germany}

(Figure 12) Steffen Hau, Mathias Hoffmann, and Stefan Seelecke, Saarland Universität, Germany, "DEA Driven Vibratory Feeder"

Vibratory feeders are widely used in part handling technology for transport, aligning and/or feeding parts to a certain process. Currently they are driven by electro-magnetic actuators and unbalance motors, which do not allow arbitrary vibration profiles or changes of amplitude/frequency during operation. Dielectric elastomer actuator (DEA) show potential to overcome these drawbacks. A fully functional DEA driven vibratory feeder transporting small goods will be demonstrated, showing DEAs potential in this new field of application. This demo received the Runner-Up Best Student Paper Award. 
Japan

(Figure 13) Minoru Hashimoto, Yi Li, Aya Suzuki, Hanako Niwa, Rina Yokotsuka, Shinshu University, Hashimoto-Tsukahara Laboratory, Nagano, Japan, "Multilayered PVC Gel Artificial Muscle"

Multilayered contraction type PVC gel actuator was

developed using stainless mesh electrodes having many positive characteristics. This include being soft and lightweight, with stable actuation in air and with high output. It is activated by applying voltage of $400 \mathrm{~V}$, and the displacement of $60-$ layer artificial muscles is $\sim 3.0 \mathrm{~mm}$, with contraction strain of $\sim 10 \%$, and the maximum output force is $\sim 50 \mathrm{kPa}$. The response rate is $9 \mathrm{~Hz}$, and the current is about $0.45 \mathrm{~mA}$. This demo

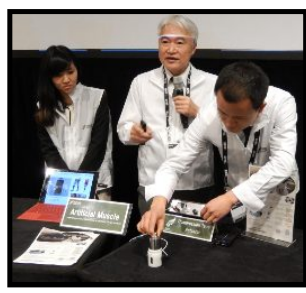

Figure 13: The Multilayered PVC Gel Artificial Muscle being presented (from Left to Right) by Rina Yokotsuka, Minoru Hashimoto, and Yi Li. received the Best EAP-in-Action Award.

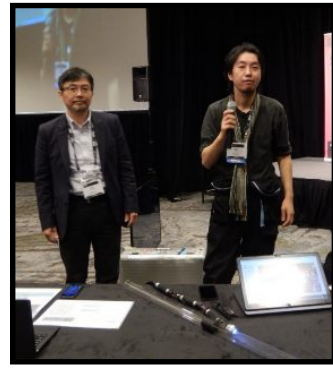

Figure 14: Tempuu Siva (on the right) and Tervo Toyoda (on the left), Haloworld Inc., presenting their Biomimetic robot system
(Figure 14) Tempuu Siva, Teruo Toyoda, and Fujio Mine, Haloworld Inc., Fukushima, Japan, "Biomimetic robot system for plumbing tests"

A tubular inchworm robot mechanism that is driven by electroactive polymer and air pressure will be presented. This robot will be equipped with a camera to allow testing the plumbing of the decommissioned Fukushima Daiichi Nuclear Power Plant. The robot is capable of traversing thru the many elbow sections along the more than several hundred meter plumbing. The use of the EAP actuation mechanism allows for smooth operation thru the curvatures along the plumbing path.

\section{New Zealand}

(Figure 15) Patrin Illenberger, Katie Wilson, Andreas Tairych, Chris Walker, Antoni Harbuz and lain Anderson, Biomimetics Laboratory, Auckland Bioengineering Institute, Auckland, New Zealand "Multilocation sensing on one input/output and EAP zoo"

The Biomimetics Lab presented:

1. The multisensor shirt that can measure stretch at several locations from one input/output.

2. The Electroactive polymer zoo: we present the latest self-regulating crawling caterpillars and wing flapping dragonflies fabricated from printed polymer and electrode. No need for electronics! This demo received the Third Place Best EAP-in-Action Award.

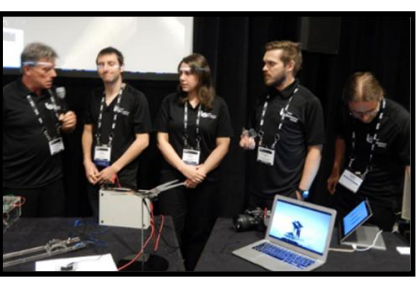

Figure 15: Iain Anderson presenting the Auckland Bioengineering Institute's Multilocation sensing on one input/output and EAP zoo. From left to right: Iain Anderson, Patrin Illenberger, Katie Wilson, Markus Henke, Andreas Tairych, and Chris Walker. 


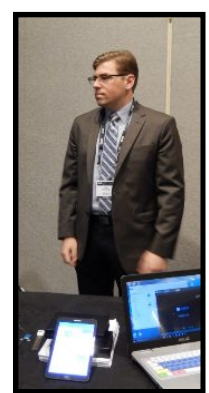

Figure 16

(Figure 16) Mark Williamson StretchSense Ltd., Auckland, New Zealand, "New EAP products"

What's new in wearable electroactive polymer sensing and energy harvesting. This included soft sensors with soft electronics.

\section{Singapore}

(Figure 17) Jiawei Cao, Lei Qin and Jian Zhu, National University of Singapore, Singapore, "Soft untethered robots"

The soft untethered robot mainly consists of a deformable robotic body and two paper-based feet. Based on the optimal mechanical design, the robot is capable of achieving autonomous movements.

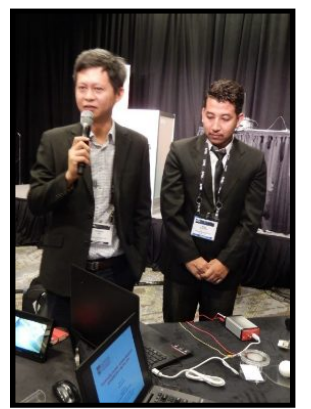

Figure 18: The Nanyang Technological University, Singapore, team presenting their electrically tuning transparency

(Figure 18) Anansa S. Ahmed and GihKeong Lau School of Mechanical and

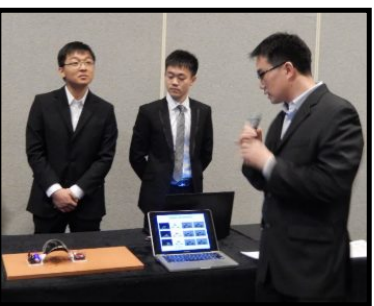

Figure 17: The team from National University of Singapore, Singapore, demonstrating their soft untethered robots. Aerospace Engineering, Nanyang Technological University, Singapore, "Dielectric elastomer grippers using tensioned arch flexures"

The followings are going to be demonstrated

1. Versatile DEA grippers with enhanced tip angle deflection and blocked force due to tension arch flexure structure.

2. Grippers capable of grasping and lifting a variety of objects including highly deformable materials without damage.

Milan Shrestha, Anansa Ahmed, Anand Asundi, Gih-Keong Lau, Nanyang Technological University, Singapore, "Electrically tuning transparency by wrinkling of $\mathrm{ZnO} / \mathrm{Ag}$ thin film"

This demonstration unit consists of transparency tunable device. It works based on wrinkling and unfolding a $\mathrm{ZnO} / \mathrm{Ag}$-coated elastomer substrate using a dielectric elastomer actuator (DEA). Initially, the membrane is at wrinkled state and the device is opaque. An object placed underneath the membrane will not be visible. When the DEA device is electrically activated, the wrinkles are flattened turning the device to a transparent membrane and the object placed behind 
the device becomes clearly visible. Reversible tuning between the two states can be obtained electrically for a large number of cycles.

\section{Switzerland}

(Figure 19) Samuel Rosset and Samuel Schlatter, EFPL, Switzerland "PetaPicoVoltron: an open-source portable highvoltage supply"

A portable high voltage power supply (HVPS) has been demonstrated that is specifically designed to drive DEAs. Its output DC voltages is up to $5 \mathrm{kV}$ with a resolution of $0.1 \%$ of full scale, and can generate square signals from $1 \mathrm{mHz}$ to $1 \mathrm{kHz}$ with a slew rate faster than $15 \mathrm{~V} / \mu \mathrm{s}$. It has a user friendly GUI enabling easy interaction with the HVPS, and using LabView library makes it simple to integrate the power supply with other instruments. The circuit layout and the software have been released as an open-source project, for anyone to use and improve.

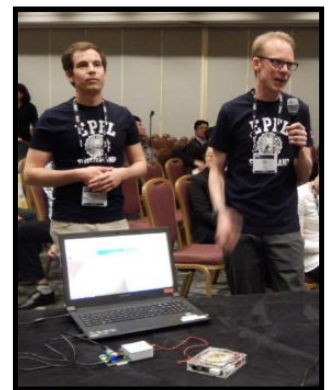

Figure 19: The EFPL, Switzerland, presenting their PetaPicoVoltron demo

\section{$\underline{\text { United States }}$}

(Figure 20) Qi Shen, Sarah Trabia, Tyler Stalbaum, Taeseon Hwang, Robert Hunt, Zakai Olsen, and Kwang Kim, University of Nevada, Las Vegas "Development of an origami soft robot using multiple shape memory ionic polymer-metal composite"

The multiple-shape-memory ionic polymer-metal composite (MSM-IPMC) actuator is used to demonstrate complex 3D deformation. The MSM-IPMC has two characteristics, which are the electromechanical actuation effect and the thermalmechanical shape memory effect. The bending,

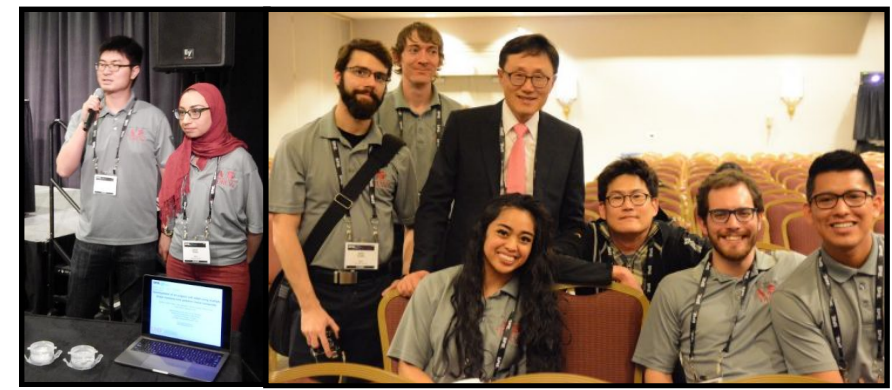

Figure 10: The team Univ. of Nevada, Las Vegas, under the lead of Kwang Kim (right) and their origami soft robot using multiple shape memory ionic polymer-metal composite (left).

twisting, and oscillating motions of the actuator could be controlled simultaneously or separately by means of thermal-mechanical and electromechanical transactions. Using the MSM-IPMC, a soft biomimetic robot was developed that has origami structure. The multiple shape memory effect enables the robot to change its shape and in return enables the robot to move forward in water. This work may bring inspiration for designing new soft robotic systems with the MSM-IPMC actuators 


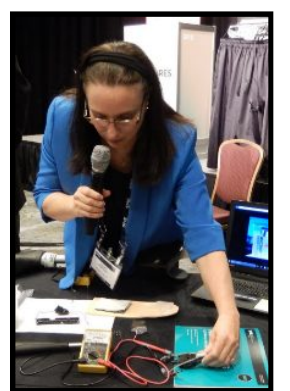

(Figure 21) Lenore Rasmussen, Ras Laboratories, "Synthetic Muscle"

The operation of the latest Synthetic Muscle based actuators was demonstrated. These are EAP based actuators that contract and expand, attenuate impact, and sense pressure. In addition, prosthetic liner prototype with self-adjusting EAP based pads and sensing robotic gripper was shown.

Figure 11: Lenore Rasmussen, Ras Labs, demonstrating her latest Synthetic Muscle based actuator, with sensing EAP pads Yoseph Bar-Cohen retrofitted to a standard EMI robotic gripper. 
Proc. of SPIE Vol. 10163 1016301-28 Downloaded From: https://www.spiedigitallibrary.org/conference-proceedings-of-spie on 26 Apr 2023
Terms of Use: https://www.spiedigitallibrary.org/terms-of-use 